DOI 10.38129/ Ann.Yur.Ist.2019.3.1.2.41

УДК 336.226.4

\title{
АКТУАЛЬНЫЕ ПРОБЛЕМЫ СОВРЕМЕННОГО НАЛОГООБЛОЖЕНИЯ В КОНТЕКСТЕ СООТНОШЕНИЯ ПУБЛИЧНЫХ И ЧАСТНЫХ ЦЕЛЕЙ
}

\author{
ЮЛИЯ ГАВРИЛЬЧЕНКО (Минск, Республика Беларусь)*
}

Собственность и культура сбережений берут начало в инстинкте самосохранения, свойственном всем живым существам. Стремление сберечь себя порождается осознанием своей индивидуальности, отделением «Я» от «не-Я». Инстинкты и жизненный опыт подсказывают оптимальные способы сохранения «Я» в целостности. При этом практически все биологические виды не только беспокоятся о сиюминутной безопасности, но организуют жизнь с определенной заботой о будущем.

Признание себя особой, но, тем не менее, конечной частью сложной окружающей действительности влечет стремление расширить свое «Я» и обеспечить его существование за счет объектов материального мира. Так возникают понятие «Мое» и желание сберечь не только Себя, но и сохранить Свое (как продолжение «Я»). В частности, с целью обеспечения продовольственной безопасности многие животные, особенно в условиях неблагоприятного климата, делают пищевые запасы. Так называемый инстинкт запасания кормов характерен для ряда насекомых, птиц, млекопитающих и др. При этом, животные с развитым коллективным началом формируют общие резервы, а «индивидуалисты» - частные.

Осознание принадлежности объекта (свое) - важный этап самоидентификации. В процессе социализации оно перерастает в противопоставление «свое-чужое» и в конечном итоге, уже в человеческом обществе, понятие владения расширяется до концепта «собственность».

Наличие объекта и осознание субъектом его принадлежности («Мое», «Наше») сами по себе не влекут появления собственности. Подобное осознание характерно как для человека, так и для некоторых других представителей животного мира. Собственность появляется именно в человеческом обществе, т.к. существование последнего обеспечивается особыми социальными регуляторами и, прежде всего, правом. Все фундаментальные характеристики собственности основаны на осознанном принятии ее неприкосновенности, вне защиты собственность становится эфемерной абстракцией. Для возникновения права нет безусловной 
необходимости наличия государства в смысле союза людей, подчиненных государственной власти 1 .

Исследователи сходятся во мнении, что первоначально возникает колективная собственность как публичный ресурс. В раннепервобытной общине условиями выживания являются тесная кооперация, коллективная собственность на землю и уравнительное или равнообеспечивающее распределение. С повышением эффективности производства, появлением специализации, возникают прибавочный продукт и трудовое распределение, а впоследствии - и обмен. В литературе высказывается мнение, что появление частной собственности исторически связано с тем этапом развития человеческого общества, когда благодаря созданию более усовершенствованных орудий труда «количество произведенного прибавочного продукта превысило количество обычно потребляемого, т.е. появились излишки»². Данное высказывание, в общем справедливое применительно к западноевропейской цивилизации, нельзя относить к Востоку, где частная собственность появляется значительно позднее. Вместе с тем, оно вполне заслуживает внимания в контексте сбережений и собственности у восточнославянских народов.

Мы полагаем, что превышение произведенного прибавочного продукта над обычно потребляемым («излищки») является не только результатом повышения производительности труда, но и следствием акта сбережения. Зарождение права колективной собственности начинается, когда каждый член общины осознает: запасы являются общими и распределяются согласно обычаю под страхом наказания. Способность и стремление присвоения части общинных сбережений, т.е. наличие (или возможность) индивидуальных сбережений и, соответственно, потребность в их защите, порождают категорию «частная собственность».

С появлением частной собственности происходит разделение публичного и частного элементов в категориях собственности и сбережений. Публичные сбережения становятся общественным (государственным) ресурсом. Сбережения домохозяйства (или индивидуума) признаются частным резервом.

1 Общзая теория права: учеб. пособие / В. А. Абрамович [и др.]; под общ. ред. С. Г. Дробязко, С. А. Калинина. Минск : БГУ, 2013. С.101-102; Пэнто, Р. Методы соииальных наук / Р. Пэнто, М. Гравитц : пер. с фр.; под ред.: Казимирчук В.П. (Вступ. ст.), Туманов В.А. (Вступ. ст.); пер.: Боботов С. В., Глазов Ю. А. М. : Прогресс, 1972. С.53-54.

2 Калибернова, О. Н. Собственность и современное российское общество (общеправовой аспект) : дис... канд. юрид. наук: 12.00.01 / О.Н. Калибернова; Нижегородск. юрид. инст. Нижний Новгород, 1999. С.14. 
С момента этого разделения возникает классическая, существующая в любом государстве дихотомия, которая характеризуется диалектическим единством (и противоречием) частного и публичного.

С одной стороны, на всех этапах исторического развития отсутствует жесткий раздел между частным и публичным. Например, еще $b$ фреоальный период государство сохраняло возможность использования сбережений населения на общественно значимые цели. В Великом княжестве Литовском достаточно активно частные сбережения привлекались для финансирования строительства дорог, мостов, защитных сооружений, для других общественно значимых целей. Массовые добровольные пожертвования в государственную казну не единожды имели место в период чрезвычайного положения вследствие войн, стихийных бедствий и в русской истории ${ }^{3}$.

С другой стороны, с развитием права (и особенно права частной собственности) все более актуальным становится максимальное ограничение возможностей изъятия публичной Властью частных накоплений. Кульминацией эволюции современной концепции права частной собственности можно признать теорию естественного права, сорормулированную английскими философами XVII в., а затем - франиузскими просветителями XVIII b., b соответствии с которой право частной собственности объявляется прирожденным, данным от природы свойством, присущим всякому человеку. Сбережения обретают полноценную правовую защиту. При этом предполагается, что для удовлетворения публичного интереса должны использоваться отдельные, публичные фонды.

Ученые полагают, что первоначально основной причиной возникновения публичных фондов стало появление в XVI в. потребности в концентрации ресурсов с целью «обеспечения наиболее насущных социальных и общеэкономических потребностей» и смысл понятийного содержания этих фондов как совокупности денежных средств, направленных на решение определенных социально-экономических целей и задач государства, не изменился в настоящее время4. Ряд проблем как общенаучного, так и прикладного характера возникает в связи с тем, что в определенном смысле к данному понятию могут быть отнесены и частные накопления.

3 Комягин Д. Л. К вопросу о понятии и классификации публичных доходов / Д. Л. Комягин / / Публично-правовые исследования. 2014. № 4. С. 77.

${ }^{4}$ Саттарова, А. А. Фонд как институт в финансовом праве : дис. ... канд. юрид. наук : 12.00.14 / А. А. Саттарова; Всероссийская гос. налог. акад. Министерсва финансов РФ. М., 2007. С. 24. 
Традиционно считается, что отношения, возникающие по поводу формирования публичных денежных фондов, охватываются правом государственных доходов. Несмотря на высказанное в литературе мнение о том, что формирование государственных доходов должно осуществляться в рамках частных имущественных отношений ${ }^{5}$ большинство авторов высказывается против использовании конструкции обязательства в финансовых отношениях, полагая, что «налоговое право тесно связано с гражданским, часто производно от него, но в то же время автономно»б.

В силу применения в процессе регулирования метода принуждения формирование публичных фондов происходит исключительно на основании нормативных правовых актов, которые детально закрепляют права и обязанности субъектов 7 . Вместе с тем, в настоящее время существует тенденция расширения источников финансирования публичных нужд. В литературе подчеркивается, что некоторые публичные потребности могут покрываться за счет не бюджета, а частных средств либо децентрализованных финансов 8 . Для подобных ресурсов применяются различные названия: сборы, платежи, парафискалитеты, квазиналоги и т.д. ${ }^{9}$

Учитывая данный факт, А.А. Нечай полагает, что публичные фонды - это специально выделенная, относительно обособленная часть денежных средств, предназначенная для удовлетворения различных видов публичного интереса. Автор относит к ним кроме государственного бюджета государственные фонды страхования банковских вкладов населения, все виды фондов обязательного страхования, золотовалютные фонды и др. ${ }^{10}$ Н.В. Васильева отмечает, что могут создаваться частные фонды денежных средств для использования в целях финансирования социально-значимых расходов (например, фонды государственных

${ }_{5}^{5}$ Иванов, А. А. Понятие «имущественные отношения» и проблемы налогового права / А. А. Иванов // Вестник ВАС РФ. 2009. № 1. С. 76-77.

${ }_{6}^{6}$ Карасева, М. В. Налоговое право России : новые аспекты правопонимания и развития / М. В. Карасева // Вестник ВГУ. Серия : Право. 2010. № 2. С. 238-239.

7 Дмитрик, О. А. Содержание и классификация финансовых правоотномении / О. А. Дмитрик; под ред. Н. П. Кучерявенко. Харьков : Легас, 2004. С.75.

${ }_{8}^{8}$ Артюхин, Р.Е. Казна и бюджет / Р. Е. Артюхин [и др.]; отв. ред.: Д. Л. Комягин. М. : Наука, 2014. C.218.

9 Крохина, Ю. А. Современные вопросы предмета финансового права / Ю. А. Крохина // Финансовое право (научно-практическии журнал Украины). 2012. № 1. С. 4-8; Корнев, А.Д. Финансово-правовое регулирование парафискалитетов в Российской Федерации: автореф. дис... канд. юр. наук: 12.00 .04 / А.Д. Корнев; Московский государственный юридический университет. Москва, 2017. С.14.

10 Нечай, А. А. Публичные фонды как системообразующая категория финансового права / А. А. Нечай // Проблемы законности. 2010. № 11. С. 110-111. 
корпораций и компаний). Несмотря на гражданско-правовую конструкцию, они действуют не в частных интересах собственника, а в «неких общих, групповых, коллективных интересах (защита вкладов, создание высокотехнологичной продукции, пенсионное обеспечение и т.п.)»11.

Н.П. Кучерявенко подчеркивает, что в данном случае мы не переносим гражданско-правовые институты в финансовое право, а выделяем для финансово-правового регулирования то, что входит в сферу финансового права12. Продолжая эту мысль, С.В. Рыбакова характеризует институт «публичных финансов» не с точки зрения формы собственности, а с точки зрения публичного (общезначимого, общественного) интереса ${ }^{13}$.

В литературе высказываются опасения по поводу данного подхода. М.В. Карасева подчеркивает, что существование квазиналоговой системы приводит к постоянному росту парафискальных платежей. Автор отмечает актуализацию проблемы возмещения государством затрат негосударственных субъектов на осуществление публичных задач. ${ }^{14}$

Как представляется, ключевым критерием негативизации в данном случае является обязательность уплаты сбора. Следует подчеркнуть, что добровольные безвозмездные поступления, хоть и могут быть отнесены к финансированию государственных расходов разных уровней 15 , и достаточно широко применялись на практике на протяжение всей истории ${ }^{16}$, не несут на себе подобного отягощения. С другой стороны, расширение системы обязательных парафискальных платежей создает дополнительную нагрузку на налогоплательщиков, что негативно сказывается не

11 Васильева, Н. В. Правовое регулирование публичных доходов / Н. В. Васильева. Иркутск: Изд-во БГУ, 2015. С.41-42.

12 Кучерявенко Н. П. Система финансового права: содержание, противоречия, перспективы / Н.П. Кучерявенко // Финансовыи механизм и его правовое регулирование: материалы Междунар. науч.-практ. конф. (24-25 апр. 2003 г.) / под ред. Е. В. Покачаловой, О. Ю. Бакаевой. Саратов: Саратовская академия права, 2003. Ч. 2. C. 4.

13 Рыбакова, С. В. Отдельные направления развития теории финансового права в аспекте определения предмета отрасли финансового права / С. В. Рыбакова // Вестник Южно-Уральского гос. университета. Серия : Право. 2009. № 17. С. 97.

14 Карасева, М. В. Некоторые тенденции развития финансово-правового регулирования на современном этапе / М. В. Карасева // Вестник МГЮА. 2014. № 4. C. 77-79.

15 Пауль, А. Г. Система доходов бюджетов / А. Г. Пауль // Вестник ВГУ; серия Право. 2011. № 2. С. 378.

16 Ягодкина, В. А. Дополнительные источники финансовых средств государственных и муниципальных учреждений / В. А. Ягодкина // Финансовое право. 2014. № 11. С. 28. 
только на экономическом росте, но и на финансовой дисииплине. Более того, даже внесение минимальной степени принудительности в данном случае может иметь отрицательный эффект.

В частности, в литературе широко обсуждается такое неоднозначное явление, как самообложение граждан17. В Республике Беларусь оно может осуществляться на основании ст. 36 Закона Республики Беларусь от 4 января 2010 г. «О местном управлении и самоуправлении в Республике Беларусь»18. По сути самообложение означает добровольное принятие обязанности уплаты налога: граждане голосуют за введение того или иного обязательного местного платежа, признавая публичные цели продолжением своего частного интереса.

Тем не менее, на практике известны случаи использования данного института для злоупотреблений со стороны публичной власти. Например, при внедрении местного сбора или налога жители района опрашиваются на предмет возражений против нововведений. В почтовые ящики вбрасываются анкеты (или бланки заявлений), которые зачастую игнорируются гражданами. По результатам налог (сбор) вводится за неимением возражений. Такой подход совершенно недопустим, поскольку формализм и злоупотребления в самообложении становятся одной из причин недоверия граждан к публичной власти и, как результат, «обеспубличиванию» частного интереса.

Важно подчеркнуть, что проявление социальной ответственности не является редким явлением и может принести реальную пользу государству, обществу и гражданам. Например, в 2016 г. около 80 \% швейцарцев проголосовали на референдуме против введения безусловного базового дохода. Властями предлагалось внедрение ежемесячных выплат гражданам Швейцарии по 2,5 тыс. швейцарских франков (порядка 2,5 тыс. долларов) для взрослых и 625 франков для детей. Однако, осознавая тяжесть сопутствующей налоговой нагрузки и важность труда $b$ целлм, швейцарцы

17 Киселев, И. А. Средства самообложения граждан в системе формирования доходов местных бюджетов / И. А. Киселев // Налоги и финансовое право. 2008. № 4. С. 225-230; Журавлева, О.О.Правовая природа самообложения / О. О. Журавлева // Финансовое право. 2012. № 10. С. 2-7; Черкасова, Ю. И., Плотникова, Н.Г. Правовые аспекты самообложения граждан / Ю.И. Черкасова, Н. Г. Плотникова // Финансовое право. 2014. № 9. С. 26-30.

18 О местном управлении и самоуправлении в Республике Беларусь [Электронный ресурс]: Закон Республики Беларусь от 4 января 2010 г. № 108-3 : в ред. Закона от 04.01.2016 № 348-3 // ЭТАЛОН. Законодательство Республики Беларусь / Нац. центр правовой информ. Респ. Беларусь. Минск, 2018. 
отказались от этой заманчивой идеи.

Повышение социальной ответственности обусловило и активное развитие института краудфандинга (от англ. «сrowd» - толпа и «funding» финансирование). Краудфандинг - народное финансирование, т.е. объединение денежных ресурсов с целью поддержки какого-либо, как правило социально значимого, проекта. Следует согласиться с В.Л. Чугреевым, что краудфандинг является одним из ответвлений краудсорсинга, т.е. совместного добровольного участия ююдей $b$ решении общественно значимых задач19. В случае краудфандинга такое участие состоит, в первую очередь, в перечислении денежных средств.

Опыт сбора денег для осуществления общественно полезных проектов имеет глубокие исторические корни. М.О. Душина в данном контексте отмечает, что еще до появления интернета коммуникация по сетевому принципу сделала возможной многие научные открытия ${ }^{20}$. Наша история знает много примеров возведения важных объектов с активным привлечением средств населения, участия граждан в финансировании других публично значимых проектов (строительство Национальной библиотеки в Беларуси, др.).

В процессе становления информационного общества данная практика достигает своего расцвета. Сам термин «краудфандинг» появился в 2006 г., хотя первый краудфандинговый веб-сервис был официально зарегистрирован в США в самом начале 2000-х гг. ${ }^{21}$ Уже по итогам 2015 г. объем мирового рынка краудфандинга превысил 34 млрд. дол. и по оценкам экспертов к 2020 г. он может составить более 90 млрд долл.

На начальном этапе краудфандинг развивается именно как общественно значимая инициатива, поэтому большую часть проектов составляют благотворительные. В этом контексте он представляет собой непосредственное использование собственности на те публичные цели, которые сам собственник считает наиболее значимыми. Процесс аккумулирования сбережений специальными финансовыми институтами

19 Чугреев, В. Л. Создание краудсорсинг-проекта для публикации и обсуждения предложений по социально-экономическому развитию региона / В. Л. Чугреев / / Проблемы развития территории. 2012. № 62. С. 157.

20 Душина, М.О. Методы сетевой коммуникации в дигитальном обществе: бенчмаркинг, краудсорсинг, краудфандинг / М. О. Душина / / Социология науки и технологий. 2014. T.5. № 1. С.105.

21 Mollick, E. The dynamics of crowdfunding: An exploratory study / E. Mollick // Journal of business venturing. 2014. Vol. 29. № 1. Р. 1; Патлис, В. В. Финансирование стартапов: теория вопроса / В. В. Патлис // Веснік Беларускага дзяржаучнага эканамічнага універсітэта. 2016. № 2. С. 51. 
или государственное участие в публичном интересе в данном случае пропускаются. Накопления сразу и напрямую инвестируются в общественное развитие (в его понимании сберегателем).

Можно утверждать, что июбая благотворительная помощь в определенной степени является способом использования публинного сберегательного ресурса. Однако применительно к краудфандингу одной из изелей становится именно всеобщая польза. Так, в случае помощи ююдям с ограниченными возможностями речь идет о новых аспектах безбарьерной среды, новационном виде инклюзивного образования, организации спортивной команды и пр. Возможна поддержка отдельных ююдей, но лишь как средство достижения публичной ијели.

В настоящее время краудфандинг отягощен рядом проблем, ключевой из которых является недостаточная защищенность прав инвесторов. Существующее правовое регулирование не предусматривает механизмов привлечения к ответственности авторов проекта, допустивших нарушения в процессе привлечения ресурсов, их распределении и реализации самого проекта. В результате даже на самых строгих краудфандинговых платформах остается большая доля проектов, которые, несмотря на полное инвестирование, даже не были начаты. Национальный банк Республики Беларусь активно работает над разработкой нормативного правового акта, регулирующего эти вопросы, однако пока проблема не имеет однозначного решения.

Тем не менее, само активное развитие краудфандинга свидетельствует о важности публичного компонента в институте частной собственности и высокой социальной ответственности людей по всему миру. Например, белорусские краудфандинговые платформы ориентированы в подавляющем большинстве на социальные проекты. Исключительно благотворительным «МаеСэнс», функционирующий с 2011 г. (maesens.by) C 2013 г. работает «Талакошт» (talaka.by). Особое место на рынке краудфандинга занимает коммерческая краудфандинговая платформа «Улей» (ulej.by), действующая по принципу известного «Kickstarter» и аккумулировавшая только за первые полгода функционирования (с апреля 2015 г.) около полумиллиарда белорусских рублей.

Важно подчеркнуть, что частная собственность и сбережения населения не могут быть признаны публичным фондом в понимании классического финансового права. Это было бы в корне ошибочным, создав теоретическую возможность для принудительного участия сбережений граждан в финансировании государственных расходов. Подобный подход, примененный в советский период, уже доказал свою неэффективность для 
реализации как частных, так и публичных интересов. Фактическая национализация дореволюционных сбережений уничтожила доверие к организованным накоплениям. Потребовались многие усилия для восстановления сберегательной традиции, которая так и не смогла полноценно трансформироваться в сберегательную культуру в условиях доминирования публичного интереса над частным.

В современный период важнейшей проблемой становится поиск баланса между частными и публичными целями в процессе правового регулирования. В литературе представлены попытки определения публичных целей через категорию интереса (от лат. interest - имеет значение, важно). Такой подход применяется достаточно часто, в различных отраслях научных знаний (философия, история, психология, управление, педагогика, юриспруденция). Публичный интерес относят к ключевым признакам публичности ${ }^{22}$. Так, П.М.Годме определяет публичные финансы как средство осуществления общего интереса ${ }^{23}$.

Понятие публичного интереса достаточно подробно исследовано, однако оно не является определенным и даже отождествляется с понятиями «частные отношения», «частное право»24. Ученые указывают на связь между публичным интересом, общественной пользой 25 и потребностями общества 26.

Как представляется, применительно к собственности определяющим является соотношение публичного и общественного. Как общественными, так и публичными в анализируемой ситуации признаются социальные, экономические и другие общие нужды (в том числе нужды государства как своего рода менеджера). В русскоязычной иитературе отмечается «исторически сложившееся отождествление терминов «государственное» и «публичное» 27. Однако данное отождествление неприменимо для других зарубежных стран: publiquе и public не значит государственный. Например, английское понятие state (государство,

22 Саурин, А. А. К вопросу о понятии «публичная собственность» / А. А. Саурин // Юридический мир. 2013. № 2. С. 8.

23 Годме, П. М. Финансовое право / П. М. Годме ; пер., вступ. ст. : Халфина Р. О. М. : Прогресс, 1978. С.77.

24 Козлова, В. Н. Понятие публичных и частных интересов и их соотношение / В. Н. Козлова // Государственная Власть и местное самоуправление. 2011. № 7. С. 36.

25 Шарнина, Л. А. Частные и публичные интересы в конституционном праве / Л. А. Шарнина // Конституизионное и муниципальное право. 2005. № 4. С. 4-6.

26 Рау, К. Г. Основные начала финансовой науки / К. Г. Рау; пер. с пятого нем. изд.; под ред. А. Корсака. Т. 1-2. СПб. : Книга по Требованию, 2012. С.3.

27 Васянина, Е.Л. Правовой режим государственных доходов на современном этапе развития финансового законодательства / Е. Л. Васянина // Налоги u финансовое право. 2012. № 11. C.207. 
государственный) в исследуемом контексте не употребляется. Интерес, цели, отношения, ресурсы являются именно публичными (public). Государство в такой интерпретации выступает не в качестве самостоятельного субъекта общественных отношений, а лишь как представитель интересов общества, уполномоченный выполнять некоторые функции. «Публичное право изначально является общим достоянием, обшим благом граждан, государству оно иишь делегируется как органу гражданской нации» 28.

Современные исследователи отмечают, что общественные интересы должны преломляться через деятельность государства ${ }^{29}$. Однако было бы b корне неверным отождествлять публичный и государственный интересы: «публичный интерес не только не тождествен государственному, но может даже противоречить ему» ${ }^{30}$.

Таким образом, публичный характер целей сбережений населения не означает их идентичности целям государства, а лишь предполагает обязательный учет последних в определении условий существования накоплений как публичного ресурса. В данном контексте реализация публичных целей также не предусматривает обязательного перехода накоплений в распоряжение государства и участия государства в сберегательном процессе.

В.Н. Козлова формулирует следующие отличительные признаки публичных интересов: принадлежат не отдельным лицам, а обществу или их идеальному единству; относятся к численно неопределенной массе людей; их реализация является условием реализации частных интересов ${ }^{31}$. О.Ю. Кравченко подчеркивает, что публичный интерес может преобразовываться в частный интерес универсального характера 32. Исследуя связь между публичным и частным интересами, Ю.А. Тихомиров называет публичный интерес концентрированным социальным обязательством публичных органов перед обществом, подчеркивая, что он не только обеспечивает устои общества и государства, но и гарантирует

28 Казанцев, Н. М. Метод финансового права: переосмысление / Н. М. Казанцев // Журнал российского права. 2012. № 6 (186). С.48.

29 Курбатов, А.Я. Сочетание частных и публичных интересов при правовом регулировании предпринимательской деятельности / А. Я. Курбатов. М.: ЮрИнфоР, 2001. 212 c.

30 Раскотиков, И. С. Публичные и частные интересы в финансовом и налоговом праве / И. С. Раскотиков / / Гражданин и право. 2014. № 10. С.67-74.

31 Козлова, В. Н. Понятие публичных и частных интересов и их соотношение / В. Н. Козлова // Государственная Власть и местное самоуправление. 2011. № 7. С. 37.

32 Кравченко, О.Ю. Публичные и частные интересы $b$ праве: политико-правовое исследование : автореф. дис. ... канд. юр. наук : 12.00 .01 / О. Ю. Кравченко ; Казанский государственный университет. Казань, 2004. С.9. 
удовлетворение частных интересов в их единичном и концентрированном («усредненном») выражении ${ }^{33}$.

В литературе в данном контексте используется понятие «общеполезности» 34 .

Мы полагаем, что понятие «общий» не является определяющим в данном случае. Гораздо важнее именно сочетание интереса индивидуального и коллективного. Таким образом, публичные изели - это стремление к удовлетворению возникающих как продолжение и развитие частных интересов в обществе и государстве, признанных публичной властью потребностей неопределенного круга ^ии, которое обеспечивает существование и прогресс соииума, а также государственное развитие. Подобное определение публичных целей предполагает, что публичный интерес может быть не только у государственных финансов, но и у частных, допуская и поощряя активное участие граждан в достижении публичных целей. Это способствует развитию общества и государства и отвечает частным интересам, способствуя защите прав и свобод человека.

\section{ЛИТЕРАТУРА}

1. Артюхин, Р.Е. Казна и бюджет / Р.Е. Артюхин [и др.]; отв. ред.: Д.Л. Комягин. - М. : Наука, 2014. - 501 с.

2. Васильева, Н. В. Правовое регулирование публичных доходов / Н. В. Васильева. - Иркутск : Изд-во БГУ, 2015. - 194 с.

3. Васянина, Е.Л. Правовой режим государственных доходов на современном этапе развития финансового законодательства / Е. Л. Васянина // Налоги и финансовое право. - 2012. - № 11. - С. 207.

4. Дмитрик, О. А. Содержание и классификаци финансовых правоотношений : моногр. / О. А. Дмитрик; под ред. Н. П. Кучерявенко. Харьков : Легас, 2004. - 157 с.

5. Душина, М. О. Методы сетевой коммуникации в дигитальном обществе : бенчмаркинг, краудсорсинг, краудфандинг / М.О. Душина // Социология науки и технологий. - 2014. - Т.5. - № 1. - С.105-115.

6. Журавлева, О. О. Правовая природа самообложения / О. О. Журавлева // Финансовое право. - 2012. - № 10. - С. 2-7;

7. Иванов, А. А. Понятие «имущественные отношения» и проблемы налогового права / А. А. Иванов / / Вестник ВАС РФ. - 2009. - № 1. - С. 76-82.

33 Тихомиров, Ю. А. Современное публичное право: монографический учебник / Ю. А. Тихомиров. Институт законодательства и сравнительного правоведения при Правительстве Российской Федерации. Москва: Эксмо, 2008. С.140.

34 Кряжков, А. В. Публично-правовые и частноправовые начала в деятельности Агентства по страхованию вкладов / А. В. Кряжков // Журнал российского права. 2013. № 1. C. 20. 
8. Казанцев, Н. М. Метод финансового права: переосмысление / Н. М. Казанцев / / Журнал российского права. - 2012. - № 6 (186). - С.48.

9. Карасева, М. В. Налоговое право России : новые аспекты правопонимания и развития / М. В. Карасева / / Вестник ВГУ. Серия : Право. - 2010. - № 2. - С. 238248.

10. Карасева, М. В. Некоторые тенденции развития финансово-правового регулирования на современном этапе / М.В.Карасева // Вестник МГЮА. 2014. - № 4. - С. 74-79.

11. Киселев, И.А. Средства самообложения граждан в системе формирования доходов местных бюджетов / И. А. Киселев // Налоги и финансовое право. - 2008. - № 4. - С. 225-230.

12. Козлова, В.Н. Понятие публичных и частных интересов и их соотношение / В.Н. Козлова // Государственная власть и местное самоуправление. - 2011. - № 7. - С. 35-38.

13. Комягин Д. Л. К вопросу о понятии и классификации публичных доходов / Д. Л. Комягин // Публично-правовые исследования. - 2014. - № 4. - С. 60-93.

14. Корнев, А. Д. Финансово-правовое регулирование парафискалитетов в Российской Федерации: автореф. дис... канд. юр. наук: 12.00 .04 / А.Д. Корнев ; Московский государственный юридический университет. - Москва, 2017. - 27 с.

15. Крохина, Ю. А. Современные вопросы предмета финансового права / Ю. А. Крохина // Финансовое право (научно-практический журнал Украины). 2012. - № 1. - С. 4-8.

16. Кряжков, А. В. Публично-правовые и частноправовые начала в деятельности Агентства по страхованию вкладов / А. В. Кряжков // Журнал российского права. - 2013. - № 1. - С. 17-20.

17. Курбатов, А. Я. Сочетание частных и публичных интересов при правовом регулировании предпринимательской деятельности / А. Я. Курбатов. М. : ЮрИнфоР, 2001. - 212 с.

18. Кучерявенко Н.П. Система финансового права: содержание, противоречия, перспективы / Н. П. Кучерявенко // Финансовый механизм и его правовое регулирование: материалы Междунар. науч.-практ. конф. (24-25 апр. 2003 г.) / под ред. Е. В. Покачаловой, О. Ю. Бакаевой. - Саратов: Саратовская академия права, 2003. - Ч. 2. - С. 3-8.

19. Нечай, А. А. Публичные фонды как системообразующая категория финансового права / А. А. Нечай / / Проблемы законности. - 2010. - № 11. - С. 109-115.

20. О местном управлении и самоуправлении в Республике Беларусь [Электронный ресурс] : Закон Республики Беларусь от 4 января 2010 г. № 108-3 : в ред. Закона от 04.01.2016 № 348-3 // ЭТАЛОН. Законодательство Республики Беларусь / Нац. центр правовой информ. Респ. Беларусь. - Минск, 2017.

21. Общая теория права : учеб. пособие / В. А. Абрамович [и др.]; под общ. 
ред. С. Г. Дробязко, С. А. Калинина. - Минск : БГУ, 2013. - 416 с.

22. Патлис, В. В. Финансирование стартапов : теория вопроса / В. В. Патлис // Веснік Беларускага дзяржауннага эканамічнага універсітэта. - 2016. - № 2. - С. 51-57.

23. Пауль, А. Г. Система доходов бюджетов / А. Г. Пауль // Вестник ВГУ; серия Право. - 2011. - № 2. - С. 370-380.

24. Пэнто, Р. Методы социальных наук / Р. Пэнто, М. Гравитц : пер. с фр.; под ред.: Казимирчук В.П. (Вступ. ст.), Туманов В.А. (Вступ. ст.); пер.: Боботов С. В., Глазов Ю. А. - М. : Прогресс, 1972. - 607 с.

25. Раскотиков, И.С. Публичные и частные интересы в финансовом и налоговом праве / И. С. Раскотиков / / Гражданин и право. - 2014. - № 10. - С. 6774.

26. Рау, К. Г. Основные начала финансовой науки / К. Г. Рау ; пер. с пятого нем. изд. ; под ред. А. Корсака - Т. 1-2. - СПб. : Книга по Требованию, 2012. - 560 с.

27. Рыбакова, С. В. Отдельные направления развития теории финансового права в аспекте определения предмета отрасли финансового права / С. В. Рыбакова // Вестник Южно-Уральского гос. университета. Серия : Право. 2009. - № 17. - C. 95-100.

28. Саттарова, А. А. Фонд как институт в финансовом праве : дис. ... канд. юрид. наук: 12.00.14 / А. А. Саттарова ; Всероссийская гос. налог. акад. Министерсва финансов РФ. - М., 2007. - 189 с.

29. Саурин, А. А. К вопросу о понятии «публичная собственность» / А. А. Саурин / / Юридический мир. - 2013. - № 2. - С. 8-12.

30. Тихомиров, Ю.А. Современное публичное право: монографический учебник / Ю.А. Тихомиров ; Институт законодательства и сравнительного правоведения при Правительстве Российской Федерации. - Москва : Эксмо, 2008. -446 c.

31. Черкасова, Ю. И., Плотникова, Н. Г. Правовые аспекты самообложения граждан / Ю. И. Черкасова, Н. Г. Плотникова // Финансовое право. - 2014. - № 9. - 26-30.

32. Чугреев, В.Л. Создание краудсорсинг-проекта для публикации и обсуждения предложений по социально-экономическому развитию региона / В. Л. Чугреев / П Проблемы развития территории. - 2012. - № 62. - С. 157-164.

33. Шарнина, Л. А. Частные и публичные интересы в конституционном праве / Л. А. Шарнина // Конституционное и муниципальное право. - 2005. № 4. - C. 4-6.

34. Ягодкина, В. А. Дополнительные источники финансовых средств государственных и муниципальных учреждений / В. А. Ягодкина / Ф Финансовое право. - 2014. - № 11. - С. 26-29.

35. Mollick, E. The dynamics of crowdfunding: An exploratory study / E. Mollick / / Journal of business venturing. - 2014. Vol. 29. - № 1. - P. 1-16. 
Dr. Prof. Yulia Gaurylchenko (Minsk, Belarus)

\section{CURRENT PROBLEMS OF MODERN TAXATION IN THE CONTEXT OF THE RELATIONSHIP OF PUBLIC AND PRIVATE GOALS}

Abstract. The article is devoted to the most important issue of modern tax policy. The author focuses on the correlation of individual and public interest. Various practices of self-taxation are analyzed. Approaches to the definition of crowdfunding and public goals are proposed. Some cases from the relevant legal practice of the Republic of Belarus are described.

Key-words: Taxes, Self-Taxation, Crowdfunding, Public Interest, Public Purpose.

проф. Юлия Гаврильченко (Минск, Беларусь)

АКТУАЛЬНЫЕ ПРОБЛЕМЫ СОВРЕМЕННОГО НАЛОГООБЛОЖЕНИЯ В КОНТЕКСТЕ СООТНОШЕНИЯ ПУБЛИЧНЫХ И ЧАСТНЫХ ЦЕЛЕЙ

Аннотация. Статья посвящена важнейшему вопросу современной налоговой политики. В центре авторского внимания корреляция индивидуального и публичного интереса. Анализируются различные практики самообложения. Предложены подходы к определению краудфандинга и публичных целей. Описаны некоторые случаи из соответствующей юридической практики Республики Беларусь.

Ключевые слова: налоги, самообложение, краудфандинг, публичный интерес, публичная цель.

проф. Юлія Гаврильченко (Мінськ, Білорусь)

\section{АКТУАЛЬНІ ПРОБЛЕМИ СУЧАСНОГО ОПОДАТКУВАННЯ В КОНТЕКСТІ СПІВВІДНОШЕННЯ ПУБЛІЧНИХ ТА ПРИВАТНИХ ЦІЛЙ}

Анотація. Стаття присвячена важливому питанню сучасної податкової політики. У центрі авторської уваги знаходиться кореляція індивідуального і суспільного інтересу. Аналізуються різні практики самооподаткування. Запропоновано підходи до визначення краудфандингу і публічних цілей. Описано деякі випадки з відповідної юридичної практики Республіки Білорусь.

Ключові слова: податки, самооподаткування, краудфандинг, публічний інтерес, публічна мета.

* Гаврильченко Юлія Петрівна - доктор юридичних наук, доцент, доцент кафедри фінансового права i правового регулювання господарської діяльності юридичного факультету Білоруського державного університету (Мінськ, Білорусь). E-mail: yuliyadovnar@rambler.ru.

DOI 10.38129/ Ann.Yur.Ist.2019.3.1.2.55

УДК 94(476+477)|19|(08) 